10-23-2015

\title{
Creating Interactive Online Instruction: The McGoogan Library Experience.
}

Teresa L. Hartman

University of Nebraska Medical Center, thartman@unmc.edu

Alissa Fial

University of Nebraska Medical Center, alissa.fial@unmc.edu

Tell us how you used this information in this short survey.

Follow this and additional works at: https://digitalcommons.unmc.edu/mcgoogan_articles

Part of the Library and Information Science Commons

\section{Recommended Citation}

Hartman, Teresa L. and Fial, Alissa, "Creating Interactive Online Instruction: The McGoogan Library Experience." (2015). Journal Articles: Leon S. McGoogan Health Sciences Library. 1.

https://digitalcommons.unmc.edu/mcgoogan_articles/1

This Article is brought to you for free and open access by the Leon S. McGoogan Health Sciences Library at DigitalCommons@UNMC. It has been accepted for inclusion in Journal Articles: Leon S. McGoogan Health Sciences Library by an authorized administrator of DigitalCommons@UNMC. For more information, please contact digitalcommons@unmc.edu. 
This is an electronic version of an article published in Hartman TL, Fial AV. Creating Interactive Online Instruction: The McGoogan Library Experience. Med Ref Serv Q. 2015 Oct-

Dec;34(4):407-17. doi:10.1080/02763869.2015.1082373. Medical Reference Services Quarterly

is available online at: http://www.tandfonline.com/doi/full/10.1080/02763869.2015.1082373 .

\title{
Creating Interactive Online Instruction: The McGoogan Library Experience
}

Teresa L. Hartman

\begin{abstract}
Alissa V. Fial
ABSTRACT. Online instruction is a hot topic at academic medical centers. Seizing the opportunity to join the online movement at the University of Nebraska Medical Center (UNMC), the McGoogan Library created an open access course made up of six learning modules. The modules addressed three issues: 1) supplementing one-shot library instruction; 2) offering opportunity for instruction when a librarian is not embedded in a course; and 3) showcasing the library as an online instruction supporter. This article discusses the planning process, technology used, how the modules were received, and how this initial project increased McGoogan Library’s involvement in the UNMC online movement.
\end{abstract}

KEYWORDS. Academic health sciences libraries, online instruction, open access courses, role of librarians

\section{Authors.}

Teresa Hartman, MLS (thartman@unmc.edu) is Education \& Research Services Librarian, McGoogan Library of Medicine, University of Nebraska Medical Center, Omaha, NE 681986705. 
Alissa V. Fial, MA, MLIS (alissa.fial@unmc.edu) is Education \& Research Services Librarian, Supervisor, Circulation Services, McGoogan Library of Medicine, University of Nebraska Medical Center, Omaha, NE 68198-6705.

This article is based on a poster presented at the Annual meeting of the Medical Library Association, Chicago, IL, May 18, 2014.

Acknowledgements. The authors gratefully acknowledge the McGoogan Library leadership for their work on and support of this project: Emily McElroy, MLS, Director; Marie Reidelbach, MLS, Professor Emerita; Heather Brown, MALS, Head of Collection Development; and Roxanne Cox, MLS, Head of Education \& Research Services. 


\section{INTRODUCTION}

When educating library users on available and valuable information resources, McGoogan Library of Medicine at the University of Nebraska Medical Center (UNMC) faces similar environmental factors shared by other health science libraries: the need to conduct library instruction in the real world that includes time limitations, limited staff to conduct instruction, and a growing student body (both on-campus and at a distance) that would benefit from online instructional support. ${ }^{1}$ In order to address these issues, McGoogan librarians recreated a one-shot library instruction session into a set of interactive learning modules. This article shares the lessons learned in order to assist others considering options to increase and strengthen their own online individualized library instruction.

McGoogan librarians have been aware of Massive Online Open Courses (MOOCs) since 2012, when library faculty began taking MOOCs to observe the instruction methods firsthand, and to experience the courses as a student would. The library team joined in campus-wide discussions on the possibilities of interactive online instruction during the two-day EDUCAUSE Learning Initiative Online Spring Focus Session on April 3-4, 2013: Learning and the Massive Online Open Course. ${ }^{2}$ Attending these sessions with other campus leaders was key to the team's understanding the need to use what was learned in order to increase the interactive component in current library instruction. The library team recognized that now was the right time and began to act on it. Using the methods discussed during the EDUCAUSE MOOC conference, they took advantage of the opportunity to expand how the library supports the university online instruction efforts. The team wanted to create interactive instruction with real-time feedback that could be used to reach students, no matter where they were located geographically. The online instruction 
modules would need to fit the campus learning management system, and should also needed to be useful to reach students before and/or after in-person instruction sessions. Strengths included: a team of librarians experienced in creating instruction using many formats (online and in person), and the ability to carve out time to complete this "duty as assigned.” McGoogan Library has a history of designing instruction for distant learners. ${ }^{3}$ Therefore, this project wasn’t introducing a new idea - just utilizing a new format coupled with the renewed intention to support the evolving campus environment.

\section{BACKGROUND}

The University of Nebraska Medical Center (UNMC) has delivered distance instruction since 1959. ${ }^{4}$ The discussions on developing MOOCs generated a high level of excitement among faculty interested in adding innovative active learning components to distance course offerings. (For readers who would like to learn more about MOOCs, Hoy wrote an excellent article: MOOCs 101: An introduction to Massive Open Online Courses. ${ }^{5}$ ) McGoogan Library has developed and consistently delivered asynchronous online instruction using video recording software and HTML since 2001. ${ }^{3}$ Intrigued by the MOOC presentation, ${ }^{2}$ the team scaled down tutorial expectations, recognizing that the library did not have the staff or the time necessary to plan for or accommodate a large number of students taking a class simultaneously in a MOOC environment. However, it would still be possible to follow a MOOC-style format, focusing on UNMC's student populations, creating pre-recorded lecture videos interspersed with quizzes to test students' knowledge, and using the lessons to supplement (or serve as proxy for) an experienced librarian providing in-person instruction. ${ }^{5}$ 
Creating an online set of lessons would address three issues: 1) supplement one-shot library instruction events; 2) provide an opportunity for instruction even when a librarian is not embedded in a course; and 3) showcase the library on campus as a key player in supporting the growing focus on online instruction. ${ }^{6}$ By reviewing the literature, the library team realized that more interactive online lessons needed to be developed in order to keep students' attention and to increase learning retention. The team incorporated the guidance found in the published research on MOOCs, as well as the methods that consisted of good online instruction. ${ }^{7}$

Setting out on this project involved an element of risk-taking and was met head-on by the team members and their sense of adventure. The team included four Reference/Education Committee members, with a combined total of 77 years of librarianship. All members had experience with educational technology as instructors and as students, as well as using online instruction methods. Three had taken multiple MOOC offerings in order to obtain the "student" experience of a MOOC and to increase subject knowledge. Meetings began in April 2013 to discuss the options. The focus was on the creation of an online learning pilot lesson that would be of interest to the widest number of students, as well as offer the greatest learning value. The pilot lesson would need to be asynchronous in order to reach all five of the UNMC campuses as well as distance students who are spread out to at least two continents.

\section{DESIGNING THE TUTORIAL}

The team developed the educational goal and objectives for the module before beginning work on the content. Close attention was spent on the objectives which would fit a wide audience. The 
learning objectives were created based on the University of Iowa's Model of Learning Objectives. $^{8}$

Goal: Create an interactive, online, PubMed tutorial that fits a wide student audience's interest and learning needs.

Objectives: Health professional students who use the McGoogan Library connection to the PubMed database will learn from this module how to construct effective searches and access full-text resources.

After completing this module, students will be able to:

- Develop a searchable question from a given problem;

- Evaluate PubMed search results and add limits to locate a particular date range, population and/or publication type;

- Use links to connect with the full-text article from a PubMed record for resources held in the McGoogan Library;

- Recognize specific sources of McGoogan Library information resource assistance.

When creating the module content, the focus was on the continuing need for PubMed instruction. PubMed crosses disciplines and is in the curricula of all UNMC colleges and schools. Also, a PubMed searching lesson would be relevant to students at all levels (serving as introduction for newer students, and a refresher for established students). Finally, PubMed is a database that students report a higher confidence in knowing how to search, while demonstrating a lack of proficiency. ${ }^{9}$ A review of current online PubMed tutorials took place. Examples included: tutorials created by McGoogan staff, those developed by the National Network of Libraries of Medicine, ${ }^{10}$ and tutorials linked off of PubMed itself. ${ }^{11}$ Noting at that time that none 
offered active learning options, the decision was made to create a tutorial which could be used on its own or as part of future flipped classroom instruction sessions.

During this time, a program was developed by UNMC’s Vice Chancellor of Academic Affairs to support the online module creation process. Course development software and hardware were purchased to support this campus-wide endeavor and installed at the new campus eLearning laboratory. The library team reviewed the tools housed at the eLearning laboratory and determined that Articulate Presenter would be the best software available to create the online modules. Articulate Presenter is a fairly easy tool and works as an add-on to PowerPoint. The group had previous experience with Jing ${ }^{\circledR}$, Adobe Captivate, and Echo360. Jing is a good tool for doing quick, small nuggets of information. The tutorials would be longer. The team did not have access to Adobe Captivate, so the restriction of purchasing software and enhancing previous skills created an additional time constraint. Finally, Echo360 did not lend itself to the easy and professional quality the team found with Articulate Presenter.

Scripts were written for searching the literature on blood clots during long airline flights. The topic was chosen based on the interest potential across health science disciplines. The scripts were divided into sections: 1) creating a basic search (covered in Modules 1 and 2); 2) an advanced search (covered in Module 3); 3) refining a search using filters (covered in Module 4); 4) getting to full text in McGoogan Library's collection and beyond (covered in Modules 5 and 6). The team chose this process in order to follow the steps of other library instructions, and to allow each module to be built upon the knowledge gained in the previous module. As an introduction, the first module demonstrated how to develop a search strategy. The Basic Search

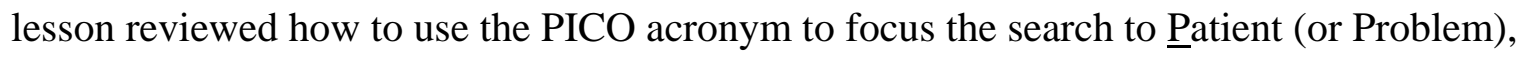
Intervention, Comparison, and Qutcome. ${ }^{12}$ Then, the lesson emphasized the importance of 
accessing the database through the library website and also reviewed what resources are included in the PubMed database. The Advanced Search included a lesson on using MeSH. There was a section instructing users on how to add Filters as a means to focus the search. Finally, the user was shown how to access full text held in the library's collection and how to request materials when they are not available.

The Articulate Presenter software lends itself to a visually appealing approach. The screen includes a menu bar on the left-hand side of the column. Individuals can select where to go from there, and the menu bar works as a Table of Contents to check previous and future slides. There are volume controls as well as a previous and next button to help the user move through the tutorial screens. Finally, at the bottom is a bar that changes color as the slide appears in order to indicate the progression of the lesson. The last module sends a user to a tutorial, which is a case study based upon what was previously learned. The tutorial utilizes Guide on the Side software, which is an open source tool from the University of Arizona. The tutorial allows the user to view the actual library website, with a guide on the left-hand side to follow for directions. The tutorial is presented as a case study in order to allow the user additional experience and take what he or she has learned and apply it a situation similar to what he or she will experience in the future (see the links below for more information).

After completing the scripts, the library team borrowed a method from theater and met in “table read" sessions to revise the lessons (example, changing to conversational rather than directive voice) and began adding instructional design elements, including quizzes to reinforce key concepts. ${ }^{13}$ Interactive quizzes were chosen to add the active learning component to the modules. ${ }^{14}$ The table read sessions ensured proper lesson flow of each module's content, and enabled the insertion of interactive knowledge checks. ${ }^{15}$ 
After several table read sessions, the team was ready to create the first set of slides to prepare for narration. Two members took the lead on this process, with one creating the slides and the other as narrator. First, the slides for each module were created and shared among the team members. Then the team would meet for additional table read sessions. At each table read, the slide creator reviewed the script to note where each slide ended and the next one began. The team kept in mind the visual content that should be included on each slide, and how to attach the scripts to each slide. The library team discussed and suggested edits to the visual appearance of the slides, based on previous experiences and preferences. For example, selecting the design standard of light letters on dark background was chosen for reading ease. The team reviewed and approved the images for fundamental concepts, such as truncation and Boolean searching. When slides were finished, the team met and reviewed the storyboard of each module, making additional edits where necessary. Next, one team member began to record the narration, using Articulate Presenter. This process proved much more involved than anticipated.

- Sound level was inconsistent when the narrator re-recorded to edit a lesson;

- Every time a slide was edited, the narration had to be completely redone;

- One cannot multi-task while recording lessons - narrating takes focus and time away from all other duties.

\section{IMPLEMENTATION AND EVALUATION PLAN}

As the slide and narration team leaders brought the modules to life, other team members applied for an IRB exemption to conduct research on how students perceived this different mode of instruction. Graduate students were selected as the first audience to evaluate the modules due to 
the fact that they have more experience with PubMed instruction sessions during their educational career and would be better equipped to report their instruction mode preferences as compared to this new method. The survey was developed in December 2013, and delivered with the modules to a group of graduate students during January 2014 (see Appendix for survey questions). The team reviewed survey results during February. The slide and narration team

leaders edited and re-recorded all modules in March, modifying the visual and audio portions of the modules based on the student suggestions and survey results.

\section{Modules: Table of Contents}

Module 1: Developing a Search Strategy

http://webmedia.unmc.edu/library/Module1/presentation.html

Module 2: Basic Searching in PubMed

http://webmedia.unmc.edu/library/Module2/presentation.html

Module 3: Advanced Searching Using MeSH in PubMed

http://webmedia.unmc.edu/library/Module3/presentation.html

Module 4: Advanced Searching Using Filters in PubMed

http://webmedia.unmc.edu/library/Module4/presentation.html

Module 5: Accessing Articles in PubMed 
http://webmedia.unmc.edu/library/Module5/presentation.html

Module 6: Requesting Articles Through McGoogan Docs

http://webmedia.unmc.edu/library/Module6/presentation.html

\section{FINDINGS}

Thirteen graduate students replied to the January 2014 user survey. Students reported feeling comfortable with PubMed before viewing the modules (46.2\%). A higher number reported feeling very comfortable with PubMed after viewing the modules (61.5\%). Written comments received from the students included:

"I liked that they were very simple yet explicit in the instruction. It made these search techniques very easy to understand.”

"It was a nice refresher."

"I love that the modules include screenshots so that it is very clear what will actually look like when the search is done.”

"Mispronunciation of the word 'venous' is a bit irritating."

"I learned about Boolean terms and that they must be capitalized. I learned how to use filters and MeSH which I had never done before. I also learned that I should access PubMed through the UNMC website. Overall, these modules were very helpful. :)”

After editing the lesson using the feedback gathered from the survey, the modules were launched for the first time as part of a summer orientation class for the Nursing PhD program. 
The students offered verbal feedback that the tutorials were very helpful, leading to additional edits. The modules became available to all students during the fall 2014 Orientation.

\section{DISCUSSION - LESSONS LEARNED}

\section{Time}

Interfiling the amount of work necessary to create interactive instruction with regular duties was anticipated to be a minor challenge. This proved to be false - creating the online instruction modules took longer than was planned. Other factors came up during the months of creating the online lessons:

- All team members had increased instruction and/or department workloads during this time. The library had five task forces going on at once.

- One member of the team become the interim library director, doubling (if not tripling) her workload.

- The team was reminded daily that there is no season in libraries where scheduling a planning meeting is easy.

- A large amount of time is required for a lesson to have a "good take."

- It became more efficient for team members to give e-mail feedback on lesson edits and changes in-between planning meetings.

- Table reads involved several sessions, each two hours long. The resulting modules' high quality made the time investment worthwhile.

\section{Quality}


- A committee served this project better than an individual. Team members pooled strengths to address and solve what individuals perceived as deficits in the modules. Solo librarians should gather a peer review group for useful feedback.

- Don’t worry too much about being perfect. ${ }^{16}$

- Let go of ego and focus on the lesson's instruction value.

\section{Technology}

- Websites and library services change. When library or information resource web pages change, entire modules have to be edited and re-recorded. McGoogan Library moved to a new e-journal link resolver during initial module creation, which meant the "getting to full text" module needed to be redesigned and re-recorded. Edits are ongoing and unending: the library moved to a new website design and changed services during the summer of 2014, which meant re-recording the modules for the nth time in 12 months.

- Sound level on the modules was not uniform. Maintaining good sound quality required using an expensive commercial microphone, which was borrowed from the UNMC campus eLearning laboratory.

\section{Usefulness}

- The tutorial was immediately useful for multiple colleges and programs.

- It was a challenge to get the word out to faculty so they could include the set of modules into their own class sites on the campus LMS. 


\section{Audience}

- The library team has used this set of modules with graduate students for an orientation with Nursing PhD students. There were six students in total that took the modules. Formal feedback was not gathered. However, students indicated the usefulness of the modules as a refresher for the material presented.

- Modules were made available to all students beginning fall 2014 through the library website. The College of Public Health placed links to the modules in their Blackboard courses beginning in the Winter Semester 2015.

\section{Impact}

- There currently is no way to reliably count usage on these tutorials. The team is exploring how to record usage. The team contacted ITS service to explore possible methods to track website statistics. The links have also been placed on LibGuides, but it is currently not possible to track LibGuides usage statistics.

- The best outcome of these modules was an increased acceptance of librarians as key players in creating online instruction. Campus leadership has continued to include faculty librarians on all of the educational technology committees. The library also has hired an Instructional Design Librarian - something that might not have happened this quickly without the online course involvement.

\section{CONCLUSION}


Increased campus development of online courses and learners located at multiple distance points precludes in-person library instruction. Librarians should develop more active/blended learning methods of instruction that is formatted to fit within or stand outside established learning management systems. Librarians also need to be flexible and resourceful enough to take advantage of new education opportunities at the time their customer base explores new methods of education delivery. Experience gained with creating this tutorial provided valuable insight into the amount of time, effort, and skills that are required to create and maintain a quality online education offering. Is the work worth doing? Yes, for two reasons: 1) it offers a method of instruction for students that the library team never have a chance to meet with or instruct, and 2) creating these online modules has led to increased library faculty involvement with universitywide virtual and interactive learning development, as well as increased the team's empathy for faculty that are creating their own online instructional materials. Going forward, the challenge will be to keep all tutorials updated while using what was learned to develop other interactive lessons.

Received: May 1, 2015

Revised: June 5, 2015

Accepted: June 19, 2015

\section{REFERENCES}


1. Dewan, Pauline, and Michael Steeleworthy. "Incorporating Online Instruction in Academic Libraries: Getting Ahead of the Curve.” Journal of Library \& Information Services in Distance Learning 7, no. 3 (2013): 278-296.

2. EDUCAUSE Learning Initiative. 2013 Online Spring Focus Session: Learning and the Massive Open Online Course. Accessed: July 12, 2013 http://www.educause.edu/events/eli2013-online-spring-focus-session.

3. Shaffer, Janette, Kate Finkelstein, Nancy Woelfl, and Elizabeth Lyden. “A Systematic Approach to Assessing the Needs of Distance Faculty.” Journal of Library Administration 41, no. 3-4 (2005): 413-428.

4. Wittson, C. L., and R. Benschoter. "Two-way Television: Helping the Medical Center Reach Out.” American Journal of Psychiatry 129, no. 5 (1972): 624-627.

5. Hoy, Matthew B. "MOOCs 101: An Introduction to Massive Open Online Courses.” Medical Reference Services Quarterly 33, no. 1 (January-March 2014): 85-91.

6. Bolliger, Doris U., and Supawan Supanakorn. "Learning Styles and Student Perceptions of the Use of Interactive Online Tutorials.” British Journal of Educational Technology 42, no. 3 (2011): 470-481.

7. King, Samuel, Richard Kaplan, and Kathleen MacDonald. “Teaching PubMed in Cyberspace: The Development of a Self-Learning Package.” Medical Reference Services Quarterly 27, no. 3 (Fall 2008): 272-283.

8. Center for Excellence in Learning and Teaching, Iowa State University. “A Model of Learning Objectives.” Accessed: September 1, 2013. http://www.celt.iastate.edu/teachingresources/effective-practice/revised-blooms-taxonomy/. 
9. Lawrence, Janna C., and Linda S. Levy. "Comparing the Self-described Searching Knowledge of First-year Medical and Dental Students Before and After a MEDLINE Class.” Medical Reference Services Quarterly 23, no. 1 (Spring 2004): 73-81.

10. National Network of Libraries of Medicine. "National Library of Medicine Training Center: Tutorials and Recordings.” Accessed: August 11, 2013. http://nnlm.gov/ntc/tutorialsrecordings/\#ch.

11. U.S. National Library of Medicine. "PubMed Online Training.” Accessed: September 20, 2013. http://www.nlm.nih.gov/bsd/disted/pubmed.html.

12. Tuttle, Brandi D., Megan Von Isenburg, Connie Schardt, and Anne Powers. "PubMed Instruction for Medical Students: Searching for a Better Way.” Medical Reference Services Quarterly 28, no. 3 (July-September 2009): 199-210.

13. Le, Mé-Linh. “The Use of Anonymous Pop-quizzes (APQs) as a Tool to Reinforce Learning.” Journal of the Medical Library Association 100, no. 4 (October 2012): 316-319.

14. Blevins, Amy, and Megan E. Besaw. "Reflecting on Quiz Placement in Online Tutorials: Creating a More Active Learning Experience.” Medical Reference Services Quarterly 30, no. 3 (July-September 2011): 316-324.

15. Pintz, C., and L. Posey. "Preparing Students for Graduate Study: An eLearning Approach.” Nurse Education Today 33, no. 7 (2013): 734-738.

16. Ransom, Daniel. "Flipped Classrooms Panel.” Presented at the California Conference on Library Instruction, Oakland, CA, April 18, 2014.

\section{Appendix}

\section{PubMed Module Survey}


Q1. What did you like about these modules?

Q2. What did you dislike about these modules?

Q3. What did you learn from these modules?

Q4. What was your comfort level with PubMed prior to completing these modules? Not comfortable | Comfortable | Very comfortable

Q5. What is your comfort level with PubMed after completing these modules? Not comfortable | Comfortable | Very comfortable

Q6. Would you recommend that others complete these modules? Yes | No | If not, why? 